\title{
Produção científica sobre Ensino de Ciências BIOLÓGICAS: UM ESTUDO DOS ANAIS DOS WORKSHOPS E SEMINÁRIOS ESTADUAIS DO IFMT
}

\author{
SCIENTIFIC PRODUCTION ON TEACHING BIOLOGICAL SCIENCES: A STUDY \\ OF THE ANNALS OF IFMT WORKSHOPS AND STATE SEMINARS
}

DOI: http://dx.doi.org/10.23926/RPD.2526-2149.2018.v3.n2.p665-680.id267

\section{Vívia Lúcia Juvino de Lemos Cardoso \\ Especialista em Ensino de \\ Ciências da Natureza. \\ vivialucia@hotmail.com}

\section{Jorge Souza de Jesus}

Especialista em Ensino de

Ciências da Natureza.

j.org@hotmail.com

\section{Fernando Henrique Cardoso}

Mestre em Matemática

Aplicada.

Professor EBTT (IFMT). fernando.cardoso@pdl.ifmt.e du.br
Resumo: É notável que, no Brasil, o número de trabalhos na área de Ciências Biológicas, fruto de pesquisas em programas de pósgraduação, grupo de pesquisas, cursos de graduação, projetos de extensão ou de qualquer outro espaço científico, têm crescido consideravelmente nestes últimos anos. Em Mato Grosso, dentre diversas Instituições de Ensino Superior, o Instituto Federal de Mato Grosso (IFMT) também é responsável por uma parcela das publicações. Diante disto, este trabalho de caráter bibliográfico e do tipo "Estado do Conhecimento", tem por objetivos mapear e delinear um perfil ou tendência das publicações voltadas para o Ensino de Ciências Biológicas, e apresentadas entre 2013 e 2017 nos eventos científicos de nível estadual, em que houve a participação da PróReitoria de Ensino do IFMT na organização. Os resultados obtidos demonstram que o perfil delimitado através desse estudo, têm aspectos semelhantes aos delineados pelo "Estado da Arte" da área de Ciências Biológicas, em periódicos nacionais apresentados por Sales et al. (2011), ou em dissertações e teses estudados por Teixeira e Megid Neto (2012).

Palavras-chave: Estado do Conhecimento. Ensino. Ciências Biológicas.

\begin{abstract}
It is notable that in Brazil, the number of works in the area of Biological Sciences, the result of research in graduate programs, research groups, undergraduate courses, extension projects or any other scientific space, have grown considerably in the latter years. In Mato Grosso, among several institutions of higher education, the Federal Institute of Mato Grosso (IFMT) is also responsible for a portion of the publications. In view of this, this work of bibliographical character and the "State of Knowledge", aims to map and outline a profile or trend of publications focused on Teaching Biological Sciences, and presented between 2013 and 2017 at state level scientific events, in which there was the participation of the Pro-Rector of Teaching of the IFMT in the organization. The results show that the profile delimited through this study, have similar aspects to those outlined by the State of the Art of the Biological Sciences area, in national journals presented by Sales et al. (2011), or in dissertations and theses studied by Teixeira and Megid Neto (2012).
\end{abstract}

Keywords: State of knowledge. Teaching. Biological Sciences. 


\section{INTRODUÇÃO}

É notável que, no Brasil, o número de trabalhos focando o ensino de Ciências Biológicas (Biologia), fruto de pesquisas em programas de pós-graduação, grupo de pesquisas, cursos de graduação, projetos de extensão ou de qualquer outro espaço científico, tem crescido consideravelmente nestes últimos anos. Tais pesquisas, que podem ser monografias, dissertações ou teses, quando não publicadas em periódicos de revistas científicas, são divulgadas nos anais de eventos em forma de artigo, resumo ou resumo expandido.

Diante desse elevado número de publicações, torna-se necessário investigar quanto ao desenvolvimento de novas metodologias e o conhecimento dos variados aspectos relacionados à área e, no entendimento de Nardi (2007), o conhecimento do perfil das produções na área de Ciências contribui para consolidar as pesquisas bibliográficas do tipo "Estado da Arte", que por sua vez, estabelecem as necessidades educacionais das regiões que são foco das pesquisas.

No Mato Grosso, dentre diversas Instituições de Ensino Superior, o Instituto Federal de Mato Grosso (IFMT) também é responsável por uma parcela das publicações. Analisando as produções na área de ensino, há dois eventos de nível estadual e institucional, que atraem os trabalhos de docentes e discentes desta instituição, sendo eles: Seminário das Licenciaturas do IFMT (SL's) e o Workshop de Ensino, Pesquisa, Extensão e Inovação do IFMT (WORKIF).

O SL's, que tem por objetivo criar espaços para discussão das Licenciaturas no IFMT, surgiu das ações previstas no projeto submetido pelos docentes do curso de Licenciatura em Ciências da Natureza (LCN), do IFMT, Campus São Vicente, Centro de Referência de Jaciara (CRJAC), à Coordenação de Aperfeiçoamento de Pessoal de Nível Superior (CAPES), para participação no Programa de Consolidação das Licenciaturas (PRODOCÊNCIA).

A organização do I SL's, realizado em 2016, foi resultado da colaboração dos professores do curso LCN do CRJAC com a Pró-Reitoria de Ensino do IFMT. Os recursos provenientes dos programas da CAPES, da Pró-Reitoria de Ensino do IFMT, e do IFMT Campus São Vicente, tornou o evento Institucional e de nível estadual.

O WORKIF, um evento institucional em que a primeira edição foi realizada em 2010 e dava ênfase apenas à pesquisa aplicada, a partir da sua terceira edição, o III WORKIF, instituiu o marco que representou sua consolidação: foram inseridas na programação a extensão e o ensino, tornando-se um espaço para discussão dessas três vertentes no IFMT. O evento é realizado através da articulação entre as Pró-Reitorias do IFMT, tais como a de ensino, pesquisa e extensão. 
Neste sentido, surgiu a seguinte indagação - Qual é o perfil, tanto em dimensão quanto em aspecto, dos trabalhos publicados nestes eventos e que investigaram o Ensino de Biologia?

Diante disto, este trabalho de caráter bibliográfico e do tipo "Estado do Conhecimento", tem por objetivos mapear e delinear um perfil ou tendência das publicações voltadas para o Ensino de Biologia, e apresentadas entre 2013 e 2017 nos eventos científicos de nível estadual promovidos pela Pró-Reitoria de Ensino do IFMT.

\section{Estado da Arte e Estado do Conhecimento}

Para Rego (2014), após a década de 1990 a difusão da produção científica se tornou mais expressiva, consequência da facilidade que pesquisadores tiveram na divulgação de seus trabalhos através da rede mundial de computadores. Também expõe a importância de aumentar a qualidade e relevância do que se publica, visto a pressão para que professores, principalmente de programas de pós-graduação, aumentem a produção científica nos cursos em que atuam.

Quanto ao cenário das pesquisas em educação, Romanowski e Ens (2006) expõe o crescente número de eventos de educação no Brasil, tais como, seminários, congressos e cursos, também, atrelados a isto, um acentuado aumento nas pesquisas e publicações nesta área, focando formação de professores, currículos, metodologias, e demais aspectos educacionais.

Diante disso, Romanowski e Ens (2006, p. 36) apresentam algumas inquietações:

Quais são os temas mais focalizados? Como estes têm sido abordados? Quais as abordagens metodológicas empregadas? Quais contribuições e pertinência destas publicações para a área? O que é de fato específico de uma determinada área da educação, a formação de professores, o currículo, a formação continuada, as políticas educacionais?

Ainda, afirmam que, "faltam estudos que realizem um balanço e encaminhem para a necessidade de um mapeamento que desvende e examine o conhecimento já elaborado e apontem os enfoques, os temas mais pesquisados e as lacunas existentes" (ROMANOWSKI; ENS, 2006, p.36).

Frente a essa necessidade, Ferreira (2002, p.1) apresenta as pesquisas de caráter bibliográfico do tipo "Estado da Arte" e "Estado do Conhecimento":

\footnotetext{
Nos últimos quinze anos tem-se produzido um conjunto significativo de pesquisas conhecidas pela denominação 'estado da arte' ou 'estado do conhecimento. Definidas como de caráter bibliográfico, elas parecem trazer em comum o desafio de mapear e de discutir uma certa produção acadêmica em diferentes campos do conhecimento, tentando responder que aspectos e dimensões vêm sendo destacados e privilegiados em diferentes épocas e lugares, de que formas e em que condições têm sido produzidas certas dissertações de mestrado, teses de doutorado, publicações em periódicos e comunicações em anais de congressos e de seminários (FERREIRA, 2002, p. 1).
} 
De acordo com Romanowski e Ens (2006) e Ferreira (2002), as pesquisas do tipo "Estado da Arte" são recentes no Brasil e de grande importância para os pesquisadores. Ainda, para Ferreira (2002), a motivação dos pesquisadores para com este tipo de pesquisa deve-se ao fato do querer conhecer a totalidade de estudos e pesquisas em determinada área.

As pesquisas do tipo "Estado da Arte" contribuem na constituição do campo teórico e no reconhecimento da pesquisa de uma área do conhecimento. Embora existam limitações neste tipo de pesquisa, tais como, o fato de que o pesquisador não possuirá controle total sobre o objeto investigado e no máximo apresentará possíveis retratos de leituras selecionadas, havendo tantos retratos selecionados pelo pesquisador quanto leitores dispostos a lê-las, contudo isto não contrapõe ou invalida os resultados alcançados (ROMANOWSKI; ENS, 2006).

Para Ferreira (2002), a motivação para este tipo de pesquisa relaciona-se ao fato de os pesquisadores estarem movidos pelo desafio de conhecer o que já foi produzido ou do que há para pesquisar.

Quanto as pesquisas bibliográficas do tipo "Estado do Conhecimento", Soares (1989), define que, usualmente denominadas como "Estado da Arte", estas pesquisas têm por objetivos sistematizar e inventariar a produção em determinada área do conhecimento, e contribuem para compreender o estado alcançado pelo conhecimento sobre um tema e em determinado período.

O "Estado do Arte" difere do "Estado do Conhecimento" pela abrangência do estudo das produções. Segundo Romanowski e Ens (2006), o "Estado da Arte" sistematiza os dados em torno de toda uma área do conhecimento e considera todos os aspectos da produção, isto é, analisa-se produções em congressos, periódicos, dissertações e teses. O "Estado do Conhecimento" focará apenas um destes setores das publicações sobre o tema estudado.

\subsection{Produções sobre o Ensino de CiênCias Biológicas no Brasil}

Relativo as pesquisas e publicações focando o ensino de Ciências Biológicas no Brasil, tiveram início a partir da década de 70, estando diretamente relacionadas ao crescimento de programas de pós-graduação em ensino, o que acarretou em uma expressiva gama de dissertações e teses (DT’s) atualmente (TEIXEIRA; MEGID NETO, 2012).

\footnotetext{
Sem deixar de reconhecer que o crescimento em termos quantitativos representa conquista de alto valor, entendemos ser fundamental estabelecer processo reflexivo sobre a pesquisa educacional realizada no país, já que à medida que o número de estudos aumenta e cresce o volume de informações, o campo de investigação vai adquirindo densidade e é necessário parar e olhar em volta para ver o que já foi feito, mobilizando esforços para avaliar e até repensar os caminhos envolvendo a pós graduação em Ensino de Ciências no Brasil (TEIXEIRA; MEGID NETO, 2012, p.2).
} 
Segundo Sales et al. (2011), grande parcela das publicações em revistas científicas, no Ensino de Biologia, provém de grupos de pesquisa ou programa de pós-graduação, e a região que mais concentra pesquisas é a região Sudeste, com 53,3\% das publicações, enquanto a região Centro-Oeste detém 5,8\%. Além disso, constatou que a quantidade de pesquisas com os níveis de Educação de Jovens e Adultos (EJA) e Educação Infantil são pouco expressivos.

A concentração das pesquisas no Sudeste demonstra a irregularidade das publicações dentro de uma ótica geográfica, e que a criação de programas de pós-graduação em Ensino de Ciências Biológicas nas demais regiões podem diminuir essa desigualdade na pesquisa. Dentro desta hegemonia da região sudeste, os principais centros de DT's no ensino de Ciências Biológicas são a Universidade de São Paulo (USP), a Universidade Estadual de Campinas (UNICAMP), Universidade Federal de Santa Catarina (UFSC), e a Universidade Estadual Paulista (UNESP-Bauru) (TEIXEIRA; MEGID NETO, 2012).

Outro perfil interessante levantado por Teixeira e Megid Neto (2012), diz respeito ao gênero dos pesquisadores na área de Ensino em Biologia, constataram que as mulheres representam mais de $70 \%$ dos pesquisadores; também constataram que dos pesquisadores dessa área, 79\% tem formação em Ciências Biológicas.

Com relação ao que se pesquisa em Ensino de Biologia nos periódicos do Brasil, Sales et al. (2011, p. 13) destacam que "os recursos didáticos são, atualmente, o principal foco temático das pesquisas em Ensino de Biologia [...] mas, ainda existem muitas lacunas na área da pesquisa em Ensino de Biologia".

Os recursos didáticos, junto com outros focos temáticos, não estavam presentes nos levantamentos das publicações na área de Ensino de Biologia na década de 70, enquanto na década de 80 notou-se progressivo aumento na diversidade de problemáticas investigadas na área, os recursos didáticos ganharam destaque somente a partir da década de 90 (TEIXEIRA; MEGID NETO, 2012).

Sales et al. (2011) e Teixeira e Megid Neto (2012), nos respectivos estudos de periódicos e DT's, também perceberam pequena parcela das pesquisas em Ensino de Biologia direcionadas para a EJA, e enfatizaram que isto já era esperado, por perceberem tímida presença na atuação das instituições nesta modalidade de ensino.

\section{Metodologia}

Este trabalho configura-se como uma pesquisa de caráter bibliográfica do tipo "Estado do Conhecimento", pesquisas desse tipo diferem das pesquisas do tipo "Estado da Arte" pela 
abrangência no estudo dos diferentes setores das produções (teses e dissertações, periódicos, anais de congressos). Segundo Romanowski (2006, p.4), "o estudo que aborda apenas um setor das publicações sobre o tema estudado vem sendo denominado de Estado do Conhecimento".

Para o desenvolvimento do trabalho, foram ponderados os anais dos principais eventos de âmbito estadual realizados pelo IFMT entre 2014 e 2017, e que contaram com a participação da Pró-Reitoria de Ensino do IFMT, possibilitando a publicação de trabalhos na área de ensino ou formação de professores.

Justifica-se o período estabelecido entre 2014 e 2017 pela dificuldade em encontrar anais de eventos realizados entre 2008 e 2013, e pelo fato de que a ocorrência de maior concentração de publicações voltadas para a formação de professores, resultantes de eventos promovidos com a participação da Pró-Reitoria de Ensino do IFMT, terem ocorrido após 2013, visto que o IFMT é uma instituição nova e que completa em 2018 sua primeira década de existência.

Dos anais dos eventos analisados, têm-se os do WORKIF, realizado em Cuiabá/MT, e que em 2018 irá para a sua $5^{\text {a }}$ edição. Este Workshop reúne extensionista e pesquisadores de todos os câmpus da instituição. A partir do $3^{\circ}$ WORKIF, a área de ensino passou a ser mais presente nas publicações do evento, pois a partir dessa edição, foi incorporado a extensão e o ensino, e suas respectivas Pró-Reitorias passaram a colaborar na organização.

Também foram analisados os anais das edições dos SL's, realizadas em 2016 e 2017, no município de Jaciara/MT, e que teve por objetivo discutir as licenciaturas no IFMT. Este evento, proposto pelos docentes da Licenciatura em Ciências da Natureza do CRJAC, para fechamento das ações do PRODOCÊNCIA, contou como colaborador na organização a PróReitoria de Ensino do IFMT. Em suas edições, além dos recursos institucionais, os recursos oriundos da CAPES, através dos programas voltados para formação de professores, contribuíram para participação dos discentes/docentes de diversos câmpus do IFMT.

Diante disso, foram analisados os anais dos seguintes eventos:

- III WORKIF - Workshop de Ensino, Pesquisa e Extensão do IFMT (2014);

- IV WORKIF - Workshop de Ensino, Pesquisa e Extensão do IFMT (2016);

- I Seminário das Licenciaturas do IFMT, III Seminário Integrador do PIBID e III Seminário da Licenciatura em Ciências da Natureza (2016);

- II Seminário das Licenciaturas do IFMT, IV Seminário Integrador do PIBID e o IV Seminário da Licenciatura em Ciências da Natureza (2017). 
De posse dos anais citados, foi realizado um levantamento e selecionado todas as publicações voltadas para o Ensino de Biologia (Ensino Fundamental, Médio ou Superior), sendo desconsideradas pesquisas que, mesmo relacionadas com áreas da Biologia, não estivessem direcionadas ao ambiente escolar.

Através da leitura dos resumos de cada publicação selecionada e, com base nos procedimentos elaborados por Sales et al. (2011) e Teixeira e Megid Neto (2012), os trabalhos foram divididos em subáreas de Biologia (denominados neste trabalho como conteúdo) e foco temático, de acordo com o tema abordado no trabalho. Além disso, foram realizados levantamentos sobre a cidade e instituição relacionada a cada trabalho, objetivando identificar quais foram os câmpus de origem dos mesmos.

As subáreas (conteúdos) foram divididas em: Biologia Geral (quando o trabalho tomou a Biologia sem mencionar um conteúdo específico); Botânica; Zoologia; Ecologia; Anatomia, Morfologia e Fisiologia humanas; Citologia/Histologia; Bioquímica; Microbiologia; Imunologia; Genética e Biologia Molecular; Evolução; Interdisciplinar (quando envolveu Biologia); Educação Ambiental; Educação em Saúde e Educação Sexual.

Os focos temáticos utilizados, ainda segundo Sales et al. (2011), são os seguintes: currículos e programas (quando relatou do desenvolvimento ou análise da estrutura de um curso), formação de professores (quando se relacionou à aspectos de formação docente), conteúdo-método (quando tratou de formas diferenciadas de se trabalhar algum conteúdo), recursos didáticos (produção de material didático), formação de conceitos (aplicação de conteúdos), características do professor (quando analisou aspectos da docência), características do aluno (quando analisou aspectos da aprendizagem do aluno), organização da escola, organização da instituição/programa de ensino não-escolar, políticas públicas, história do ensino de Ciências, história e filosofia da Ciência e Outro.

\section{Resultados}

Dos quatro eventos considerados para esta pesquisa, ao todo, foram identificadas 63 publicações que focaram o Ensino de Biologia. Destas, 60 eram provenientes de autores associados ao IFMT.

No IFMT os cursos de Licenciatura em Ciências da Natureza, Ciências da Natureza com habilitação em Biologia ou Ciências Biológicas, são ofertados por seis campus, estando localizados nos municípios de: Jaciara (CRJAC-Campus São Vicente), Juína, Rondonópolis, Confresa, Diamantino e Guarantã do Norte. 
De acordo com a Figura 1, dessas unidades, as únicas que não apresentaram trabalhos focando o Ensino de Biologia foram as unidades de Diamantino e Guarantã do Norte, o que se justifica devido aos seus cursos de licenciatura na área terem iniciados apenas em 2017.

Quanto à representatividade das publicações de autores de cada campus nos eventos, a Figura 1 demonstra que, destas instituições, as unidades do IFMT de Jaciara, Juína e Confresa, juntas, apresentaram mais de 75\% dos trabalhos focados no Ensino de Biologia.

Figura 1- Quantidade de publicações nas edições dos I e II SL's e III e IV WORKIF por cada unidade do IFMT: Tangará da Serra (Tga), Sorriso (srs), Campo Novo do Parecis (Cnp), Pontes e Lacerda (Plc), Barra do Garças

(Bag), Rondonópolis (Roo), Cuiabá, Confresa (Cfs), Juína (Jna) e Jaciara (Jac)

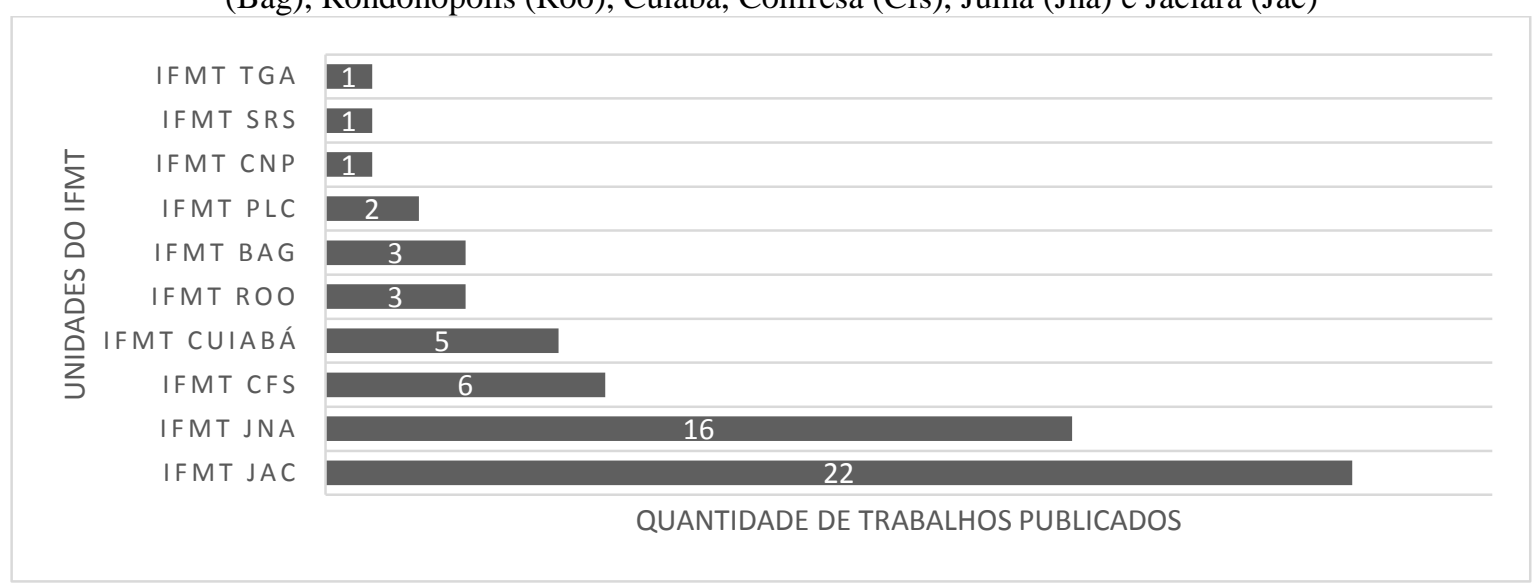

Fonte: dados da pesquisa

Cabe destacar que a unidade de Jaciara desponta como a que mais apresentou autores associados as publicações analisadas em Ensino de Biologia, também, teve várias outras publicações na área de Ciências da Natureza, focando a Física ou Química, mas que não foram computadas por não ser foco do estudo. Este resultado deve-se ao fato que na unidade existe um curso de Licenciatura em Ciências da Natureza em funcionamento desde 2010.

A unidade de Juína também se destacou quanto ao número de publicações focando o Ensino de Biologia e, segundo informações apresentadas no Projeto Político do Curso de Licenciatura em Ciências Biológicas, a primeira turma do curso ingressou em 2011.

Diante disso, confirma-se que o volume de publicações relacionadas ao Ensino de Biologia está diretamente ligado às unidades que ofertam cursos de Licenciatura na área e ao tempo da implantação dos referidos cursos, visto que, das três unidades que apresentaram maior número de publicações, conforme apresentado na Figura 1, todas tiveram seus cursos de Licenciatura iniciados há mais de 7 anos.

Por fim, relativo às publicações associadas aos autores de cada Campus do IFMT, as seguintes unidades não tiveram autores que apresentaram trabalhos focando a área de ensino de 
biologia em nenhuma das edições dos SL's ou do WORKIF: Sinop, Guarantã do Norte, Várzea Grande, Cáceres, Primavera do Leste, Diamantino, Lucas do Rio Verde, e Alta Floresta.

Das publicações analisadas, em grande parte, eram provenientes de discentes das licenciaturas do IFMT orientados pelos seus professores/ tutores, também foram identificadas publicações de egressos e de mestrandos do IFMT.

Figura 2- A: Unidades que apresentaram trabalhos no WORKIF ou no SL's, focando o ensino de Biologia. B: Unidades que concentraram maioria dos trabalhos publicados na área de ensino de Biologia
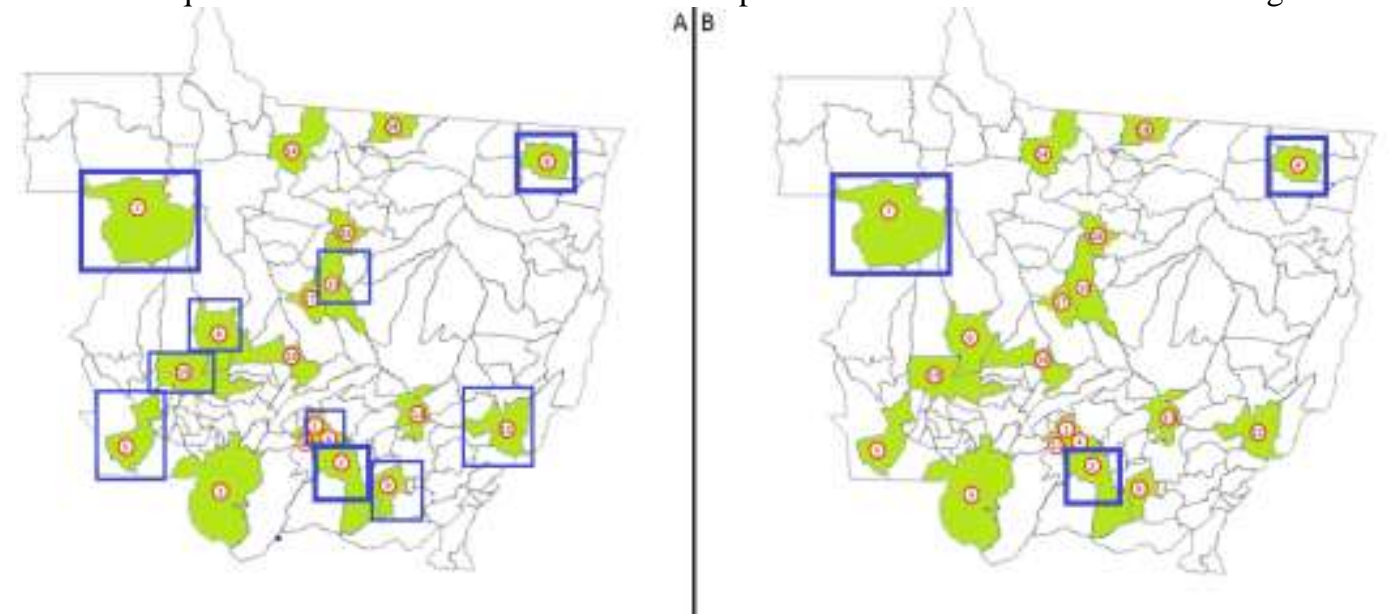

Fonte: dados da pesquisa. mapa cartográfico editado pelos autores, disponível no site do IFMT.

Analisando-se os conteúdos, através do que é apresentado na Figura 3, observa-se que a maior ênfase das publicações foi na área de Educação Ambiental, demonstrando maior interesse nessa área por parte dos pesquisadores.

Figura 3- Quantidade de publicações por área nas edições dos I e II SL’s e nos III e IV WORKIF.

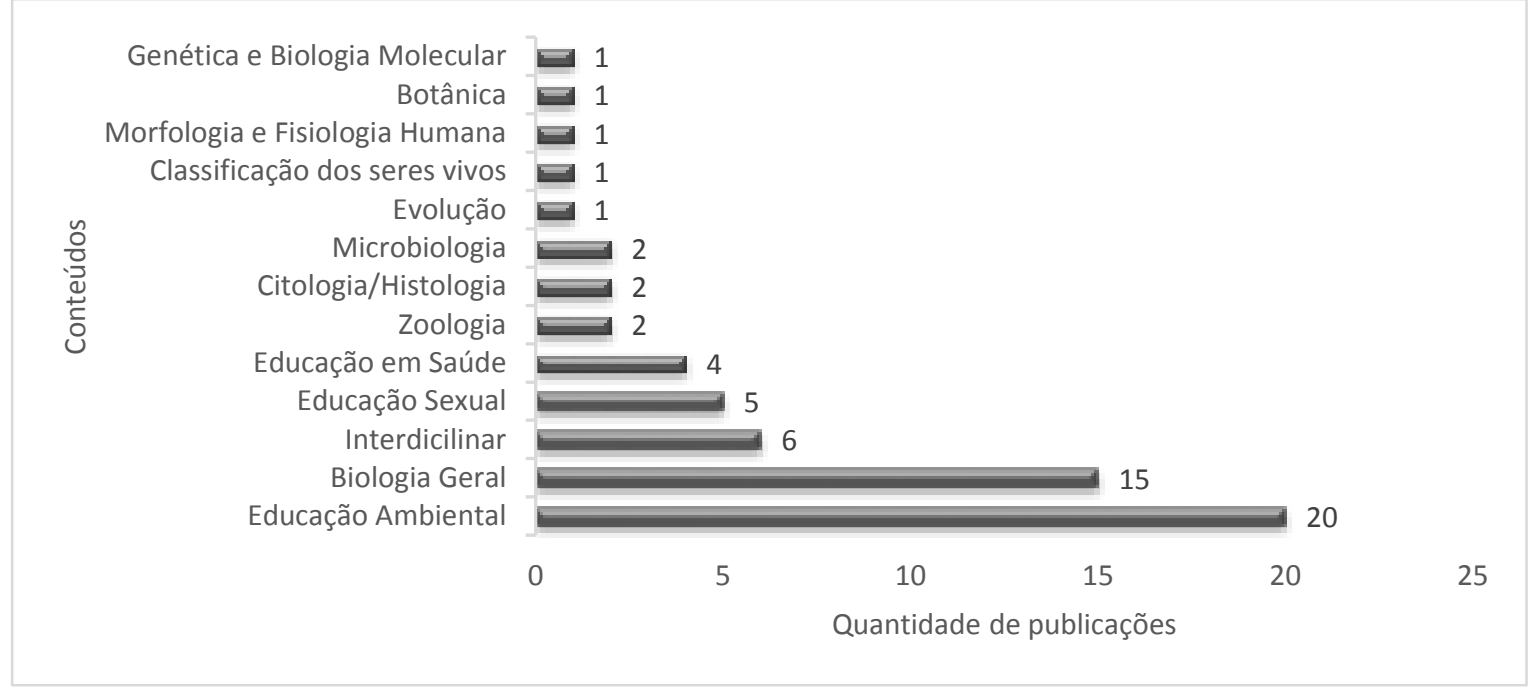

Fonte: Dados da pesquisa. 
Quanto a preferência da abordagem em Educação Ambiental, pode estar associado ao fato das instituições e autores que publicaram nos eventos, situarem-se em um estado de grande potencial agrícola e extensas áreas de lavouras, que causam vastos impactos ambientais.

Os resultados corroboram com os apresentados por Teixeira e Megid Neto (2012), onde expõem que uma parcela significativa de DT’s de Ensino de Biologia defendidas no Brasil abordaram esse conteúdo. Segundo os autores "Tais estudos revelam uma preocupação dos pesquisadores em relação ao papel do ensino de Ciências e Biologia e da própria Educação Ambiental ante a crise ambiental instalada no seio da sociedade contemporânea" (TEIXEIRA; MEGID NETO, 2012 p. 288).

Ainda, dos resultados apresentados na Figura 3, a Biologia Geral também destaca-se entre os conteúdos mais abordados nas publicações, e este resultado também é similar aos obtidos por Teixeira e Megid Neto (2012) que, nas análises das DT’s relativas ao ensino de Biologia no Brasil, constataram que a maioria dos trabalhos defendidos apresentaram uma abordagem do tipo geral, tomando o Ensino de Biologia genericamente como objeto de estudo.

Ressalta-se que dos cinco trabalhos que abordaram práticas interdisciplinares, apresentados na Figura 3 como conteúdo interdisciplinar, também podem ser enquadrados como Biologia Geral, fazendo que a Biologia Geral e a Educação Ambiental estejam na mesma proporção de publicações. Cabe destacar o interesse dos autores pela interdisciplinaridade, pois este conteúdo encontra-se entre os três mais investigados nos eventos.

Os seguintes conteúdos: Classificação dos seres vivos, Morfologia e Fisiologia Humana, Botânica e Genética e Biologia Molecular e Evolução, foram pouco evidenciados nas publicações, perfazendo um trabalho por conteúdo. Tais resultados também seguem alinhados aos apresentados por Teixeira e Megid Neto (2012), onde afirmam que a Evolução e várias outras subáreas da Biologia demandam pouca atenção dos trabalhos em Ensino de Biologia.

Embora o foco do estudo seja sobre resumos expandidos, que em sua grande maioria provém de pesquisas feitas ainda na graduação, o perfil dos conteúdos se aproxima dos trabalhos oriundos de mestrado e doutorado no Brasil, conforme apresentado por Teixeira e Megid Neto (2012), apontando que o perfil das publicações dos eventos a nível do IFMT são semelhantes aos das provenientes de programas de pós graduações do país. 
Figura 4- Quantidade de publicações por nível de ensino e focos temáticos, nos I e II SL's e III e IV WORKIF.

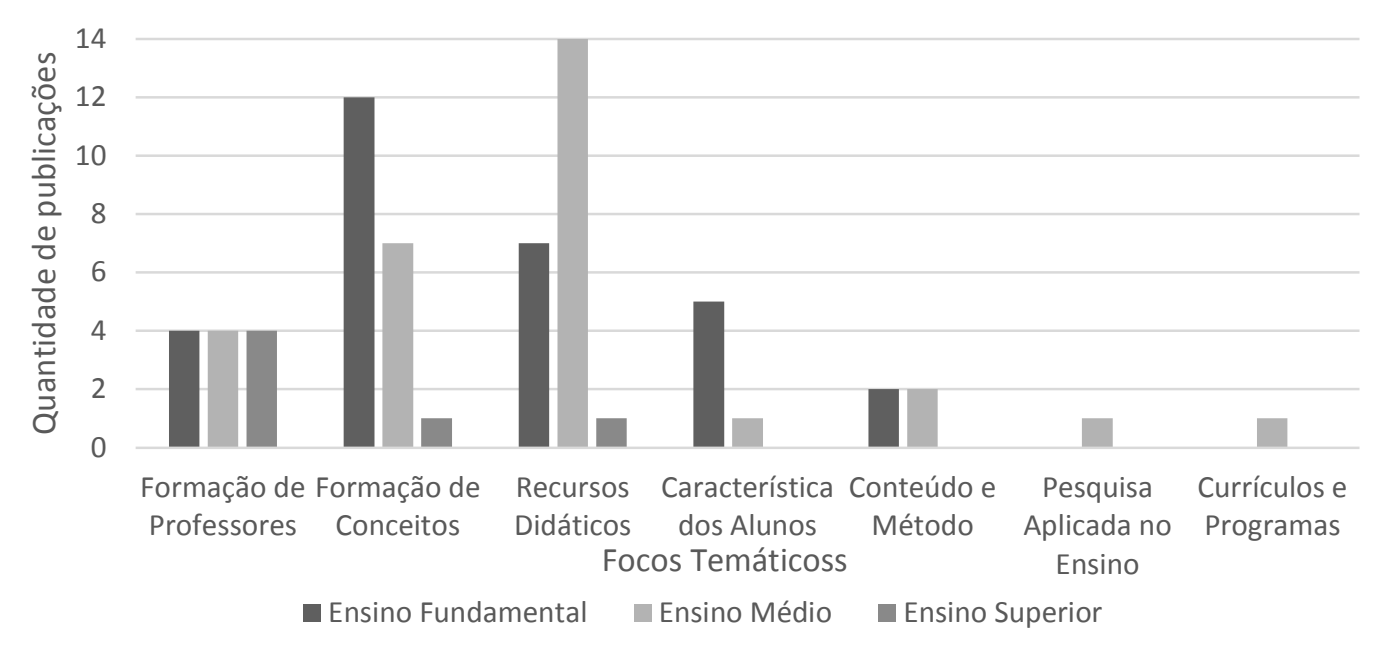

Fonte: dados da pesquisa

Quanto ao foco temático, os dados apresentados na Figura 4 apontam os recursos didáticos como a temática mais abordada nos trabalhos publicados nos WORKIF's e nos SL's, e este resultado também segue alinhado com os apresentados por Sales et al. (2011), onde, ao analisarem as publicações em periódicos nacionais sobre o Ensino de Biologia destacaram, os recursos didáticos, como o principal foco temático das pesquisas na área.

Estudos realizados por Teixeira e Megid Neto (2012), também constataram que os recursos didáticos foram um dos focos temáticos mais abordados nas DT's que investigaram o Ensino de Biologia, assim como a temática formação de professores, que na Figura 4 aparece como o terceiro tema mais abordado, reforçando que o perfil das publicações das licenciaturas do IFMT se aproxima, embora de modo não tão abrangente, das publicações nacionais provenientes de pesquisas educacionais dos programas de pós-graduação brasileiras.

Quanto ao nível de ensino onde a pesquisa foi aplicada, através dos resultados apresentados na Figura 4, observa-se que o nível de ensino fundamental e médio tiveram a mesma presença nas publicações, sendo 30 trabalhos aplicados no ensino fundamental e 30 no ensino médio. Aplicações no ensino superior totalizaram apenas 6 trabalhos, não havendo a mesma representatividade quanto aos aplicados no ensino médio ou fundamental.

Neste aspecto os dados levantados destoaram dos apresentados por Teixeira e Megid Neto (2012) e Sales et al. (2011). Enquanto Teixeira e Megid Neto (2012) perceberam maior evidência das DT's voltadas para o ensino superior, Sales et al. (2011) evidenciaram maior número de periódicos voltados para o ensino fundamental.

Não obstante, Sales et al. (2011) destacaram uma tendência de crescimento das pesquisas em Ensino de Biologia no nível fundamental, enquanto as pesquisas em Ensino 
Superior tiveram supremacia nas décadas passadas. Ainda, relaciona-se à igualdade no nível de ensino da aplicação das pesquisas, o fato do IFMT possuir cursos de Licenciatura em Ciências da Natureza com foco de atuação no ensino fundamental, e cursos de Licenciatura em Ciências Biológicas com foco de atuação no ensino médio.

Além do estudo das publicações dentro de uma perspectiva global, isto é, sem fazer distinção entre trabalhos dos SL's e dos WORKIF's, também foi relacionada algumas características das publicações por evento, conforme é apresentado adiante.

Quando se comparou o I e o II SL's, observou-se que no II SL's houve uma acentuada redução na proporção de trabalhos de Ensino de Biologia, caindo de $20 \%$ para $12 \%$ dos trabalhos publicados, embora neste período o número de licenciaturas na área tenha aumentado.

Segundo Palhares (2017), de 2016 para 2017 houve redução no número de bolsas e recursos do PIBID, o que pode estar relacionado às reduções das publicações nestes eventos.

Ao analisar a Figura 5, constata-se que a unidade do IFMT de Jaciara (Campus São Vicente) foi a que apresentou maior parte dos trabalhos voltados ao Ensino de Biologia, o que, além da existência do curso de Licenciatura em Ciências da Natureza desde 2010, também se deve ao fato das duas edições do evento terem sido realizadas neste município. Outra unidade do IFMT que apresentou uma boa quantidade de trabalhos nas edições dos SL's foi a de Juína.

Figura 5 - Instituições de Ensino Superior que foram associadas aos autores das publicações nas edições dos I e II Seminários das Licenciaturas

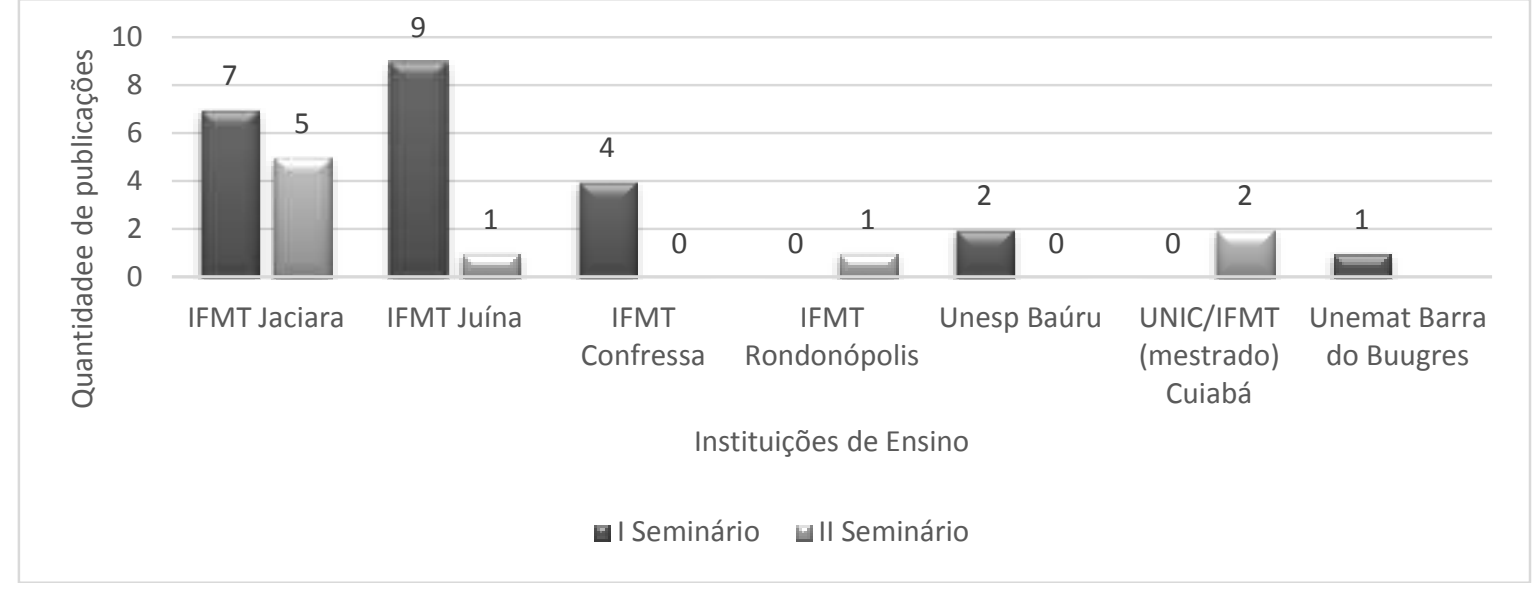

Fonte: dados da pesquisa

Estrito aos SL's, além das unidades do IFMT apresentadas na Figura 1, apenas outras duas instituições de ensino tiveram publicações de Ensino de Biologia vinculadas nos anais, sendo dois trabalhos da Unesp (Universidade Estadual Paulista) de Bauru e um da UNEMAT (Universidade Estadual de Mato Groso) de Barra do Bugres. Ressalta-se que o público alvo 
desses eventos era a nível institucional e do estado, mas que de modo positivo chamou atenção de pesquisadores instituições de ensino superior de outro estado.

Ainda, compete destacar que o autor associado a UNEMAT de Barra do Bugres era egresso do IFMT, do CRJAC (Jaciara) e, autores associados ao IFMT de Cuiabá, conforme expostos na Figura 5, eram vinculados ao programa de Mestrado em Ensino do IFMT vinculado com a UNIC, sendo estes também de egressos do CRJAC (Jaciara).

Diante do que foi apresentado, dentro da dimensão da área das Ciências Biológicas, através da análise do perfil dos autores dos trabalhos publicados nos SL's e das localidades das instituições em que estavam associados, grande parte dos autores eram discentes provenientes das licenciaturas do IFMT orientados pelos seus professores, além disso, foram identificadas uma pequena parcela de publicações provenientes de egressos, onde todos eram discentes de programas de pós graduação do IFMT.

Portanto, quanto às unidades do IFMT que tiveram os nomes associados aos autores das publicações nos SL's, se estes não eram alunos das Licenciaturas de Ciências da Natureza/ Biológicas do IFMT, então eram egressos do curso da unidade de Jaciara e estudantes de mestrado. Exceção dada apenas aos trabalhos provenientes da Unesp.

Figura 6 - A: Campus que ofertavam licenciaturas na área de Ciências Biológicas (Licenciaturas em: Ciências Biológicas, Ciências da Natureza ou Ciências da Natureza com Habilitação em Biologia). B: Unidades do IFMT que ofertam Licenciaturas na área de Ciências Biológicas e que apresentaram trabalhos nos seminários.
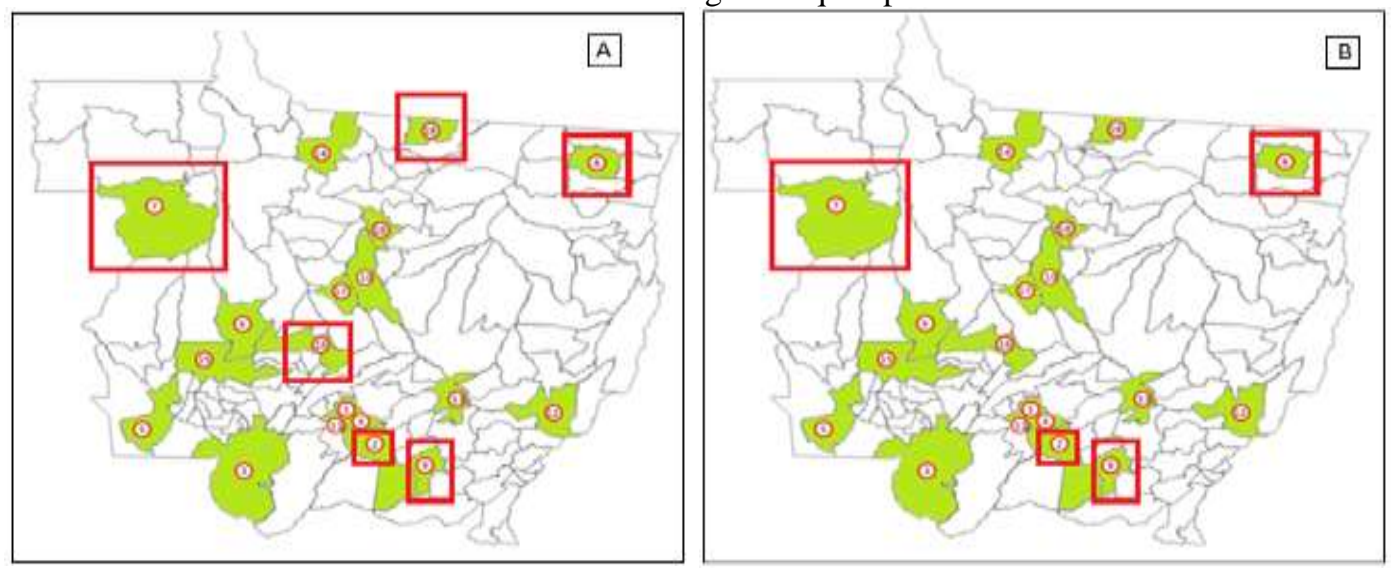

Fonte: Dados da pesquisa. Mapa cartográfico editado pelos autores, disponível no site do IFMT.

Ao analisar os conteúdos abordados nas publicações do II SL's, foi observado certa homogeneidade, podendo estar relacionado ao fato de que a maioria dos trabalhos publicados foram do curso de Licenciatura em Ciências da Natureza da unidade de Jaciara, e isto pode indicar um perfil das produções acadêmicas desse curso, em que tal problemática pode ser respondida através de um "Estudo do Conhecimento" dos trabalhos de conclusão do curso. 
Figura 7 - Quantidade de publicações de cada Campus do IFMT nas edições dos III e IV WORKIF

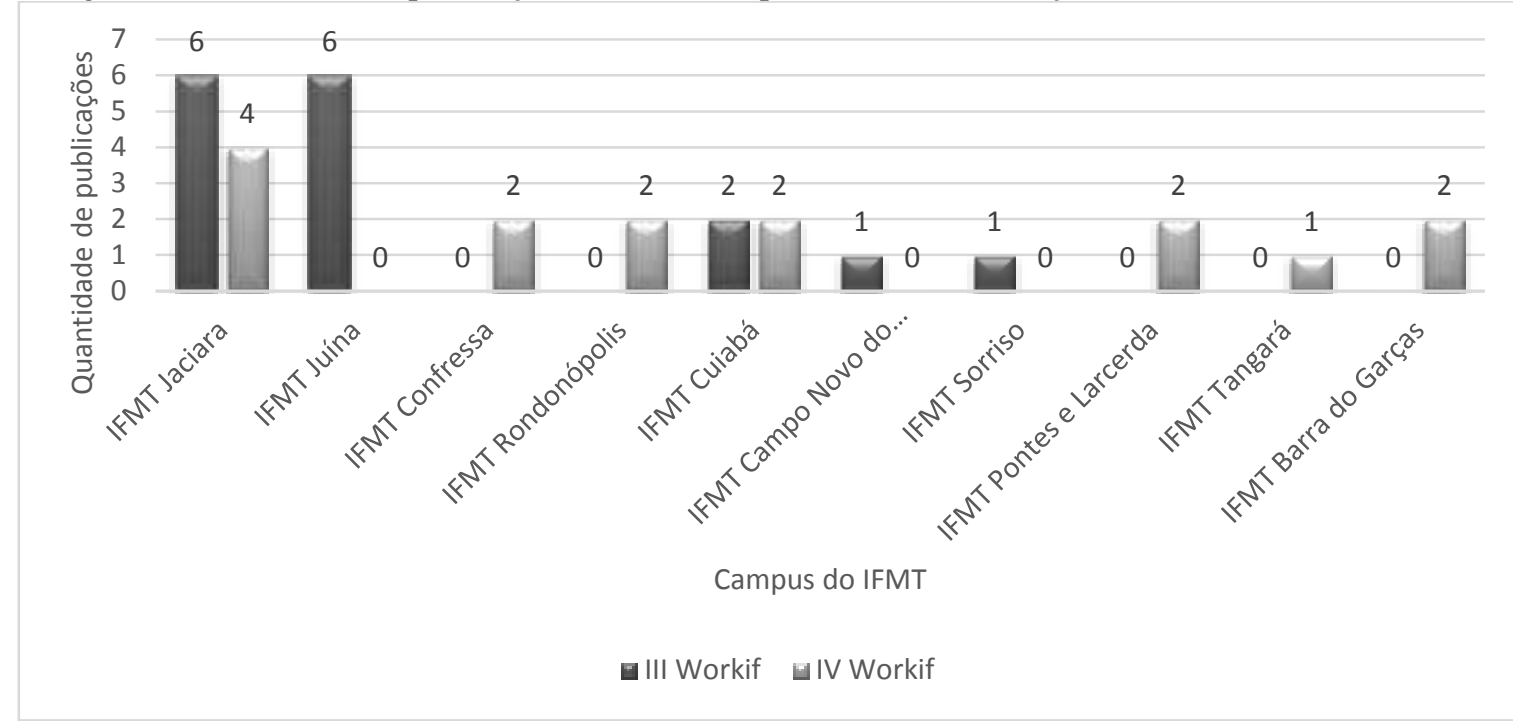

Fonte: Dados da pesquisa.

Quanto ao WORKIF, as unidades do IFMT de Jaciara e de Juína, assim como foi nos SL's, são as que mais produziram trabalhos na área de Ensino de Biologia. Contudo, várias unidades que não ofertam cursos na área de Licenciatura em Ciências Biológicas apresentaram trabalho focando o Ensino de Biologia, como é o caso do IFMT de Cuiabá, Campo Novo dos Parecis, Sorriso, Pontes e Lacerda, Tangará da Serra, e Barra do Garças.

Ambos os eventos tiveram quase o mesmo número de trabalhos focando o Ensino de Biologia, enquanto nos seminários foram 32, no WORKIF foram 31 publicações, contudo os conteúdos abordados nas publicações do WORKIF foram diversificados, diferente dos SL's que apresentaram certa homogeneidade.

\section{CONSIDERAÇÕES FINAIS}

O estudo possibilitou identificar que, dos resumos expandidos que focam o Ensino de Biologia e foram publicados em eventos de nível estadual promovidos pelo IFMT, grande parte são oriundos de produções de graduandos dos cursos de licenciatura e que, desconsiderando a qualidade ou aprofundamento da pesquisa, seguem o mesmo perfil, quanto ao foco temático, conteúdos ou público estudado, das dissertações, teses ou periódicos publicados no Brasil.

Ainda, o número de publicações nesses eventos institucionais voltadas para o Ensino de Biologia, estão diretamente associadas aos câmpus que ofertavam Licenciatura em Ciências Biológicas ou Ciências da Natureza, destacando-se as produções provenientes do IFMT, Centro de Referência de Jaciara, e do Campus de Juína. Ambas as unidades englobam a maior parte das produções nesta área. 
Por fim, foi percebido que o número dessas produções teve impacto negativo à medida que foi reduzido as bolsas do PIBID, podendo estar associado tantos aos custos que os discentes têm para se deslocar às cidades que cediam os eventos ou a disponibilidade de atuar em pesquisas, visto que sem bolsas do programa muitos deixam de realizar pesquisas.

Quanto aos conteúdos abordados nas publicações, observou-se que a área de Ensino de Biologia com mais publicações foi a de Educação Ambiental, sendo seguida pela área de Biologia Geral. Tais resultados mostraram a preocupação dos pesquisadores com as questões ambientais, visto que os locais de onde esses trabalhos são provenientes, são conhecidos por apresentarem grande área voltada à agricultura. Analisando-se as temáticas abordadas nos trabalhos selecionados, notou-se um grande número de publicações focadas no tema recursos didáticos, seguido por formação de conceitos e formação de professores.

O ensino básico foi o mais representado em relação ao foco das pesquisas, sendo que o número de trabalhos voltados ao ensino superior não foi significativo. Em última análise, os resultados obtidos vão ao encontro do perfil das publicações nacionais voltadas ao Ensino de Biologia, tanto em relação ao tema abordado, quanto em relação ao público alvo dos trabalhos.

\section{REFERÊNCIAS}

FERREIRA, N. S. As pesquisas denominadas "Estado da Arte". Educação \& Sociedade, São Paulo, v. 23, n. 79, p. 257-272, ago. 2002. Disponível em: <http://www.scielo.br/pdf/es/v23n79/10857.pdf>. Acesso em: 19 ago. 2018.

SEMINÁRIO DAS LICENCIATURAS DO IFMT, 1, 2016, Jaciara-MT. Anais do I Seminário das Licenciaturas do IFMT/ III Seminário Integrador do PIBID IFMT/ III Seminário da Licenciatura em Ciências da Natureza. Jaciara: IFMT, 345p.

SEMINÁRIO DAS LICENCIATURAS DO IFMT, 2, 2017, Jaciara-MT. Anais do II Seminário das Licenciaturas do IFMT/ IV Seminário Integrador do PIBID IFMT/ IV Seminário da Licenciatura em Ciências da Natureza. Jaciara: IFMT, 295p.

NARDI, R. A área de ensino de ciências no Brasil: fatores que determinaram sua constituição e suas características segundo pesquisadores brasileiros. In: NARDI, R. (Org). A pesquisa em ensino de Ciências no Brasil: alguns recortes. São Paulo: Escrituras, 2007. p. 357-412.

PALHARES, I. Programa de bolsas para professor tem redução de 14,8\%. Folha de São Paulo, São Paulo, 17 ago. 2017. Folha Educação. Disponível em: <https://educacao.estadao.com.br/noticias/geral,programa-de-bolsas-para-professor-temreducao-de-14-8,70001939431>. Acessado em: 22 ago. 2018.

REGO, T. C. Produtivismo, pesquisa e comunicação científica: entre o veneno e o remédio. Educação e Pesquisa, São Paulo, v. 40, n. 2, p. 325-346, abr./jun. 2014. Disponível em: 〈http://www.scielo.br/pdf/ep/v40n2/v40n2a03.pdf >. Acessado em: 12 set. 2018. 
ROMANOWSKI, J. P.; ENS, R. T. As pesquisas denominadas do tipo "estado da arte" em educação. Revista Diálogo Educacional, Curitiba, vol. 6, n. 19, p. 37-50, set./dez. 2006. Disponível em: < http://www.redalyc.org/pdf/1891/189116275004.pdf>. Acessado em: 13 jul. 2018.

SALES, A. B. et al. Tendências atuais da pesquisa em ensino em biologia: uma análise preliminar de periódicos nacionais. In: Colóquio Internacional Educação e Contemporaneidade, 5, 2011, São Cristóvão, Ceará. Anais do V Colóquio Internacional Educação e Contemporaneidade. Sergipe: EDUCON, 2011. p. 1-5. Disponível em: $\langle$ https://ri.ufs.br/bitstream/riufs/8731/2/TendenciasAtuaisEnsinoBiologia.pdf $>$. Acesso em: 13 jul. 2018.

SOARES, M. Alfabetização no Brasil - O Estado do conhecimento. Brasília: INEP/MEC, 1989.

TEIXEIRA, P. M. M.; MEGID NETO, J. O estado da arte da pesquisa em ensino de Biologia no Brasil: um panorama baseado na análise de dissertações e teses. Revista Electrónica de Enseñanza de las Ciencias: Universidade de Vigo. Espanha, v. 11, n. 2, p. 273-297. 2012. Disponível em: 〈http://reec.uvigo.es/volumenes/volumen11/REEC_11_2_2_ex500.pdf>. Acesso em: 10 jul. 2018.

WORKSHOP DE ENSINO, PESQUISA, EXTENSÃO E INOVAÇÃO DO IFMT, 4, 2014, Cuiabá. Anais do III WORKIF- Workshop de Ensino, Pesquisa, Extensão e Inovação do IFMT. Cuiabá-MT: IFMT, 2014. 1210 p.

WORKSHOP DE ENSINO, PESQUISA, EXTENSÃO E INOVAÇÃO DO IFMT, 4, 2016, Cuiabá. Anais do IV WORKIF- Workshop de Ensino, Pesquisa, Extensão e Inovação do IFMT. Cuiabá-MT: IFMT, 2016. 1127 p.

Recebido em: 2 de outubro de 2018. Aprovado em: 26 de novembro de 2018. 